Note

\title{
Development of a Quantitative PCR Assay for Thermophilic Spore-Forming Geobacillus stearothermophilus in Canned Food
}

\author{
MIYO NAKANO* \\ Division of Food Science, Toyo Institute of Food Technology, 23-2, 4-chome, \\ Minami-hanayashiki, Kawanishi, Hyogo 666-0026 Japan
}

Received 16 December, 2014/Accepted 28 April, 2015

\begin{abstract}
The thermophilic spore forming bacteria Geobacillus stearothermophilus is recognized as a major cause of spoilage in canned food. A quantitative real-time PCR assay was developed to specifically detect and quantify the species G. stearothermophilus in samples from canned food. The selected primer pairs amplified a 163-bp fragment of the 16S rRNA gene in a specific PCR assay with a detection limit of $12.5 \mathrm{fg}$ of pure culture DNA, corresponding to DNA extracted from approximately $0.7 \mathrm{CFU} / \mathrm{mL}$ of $\mathrm{G}$. stearothermophilus. Analysis showed that the bacterial species G. stearothermophilus was not detected in any canned food sample. Our approach presented here will be useful for tracking or quantifying species G. stearotethermophilus in canned food and ingredients.
\end{abstract}

Key words : Geobacillus stearothermophilus / Flat sour spoilage / Real-time PCR / Spore-forming thermophilic bacteria.

The spoilage control and production safety in the canning industries are based on the simple principles: a minimal heat-treatment for low-acid foods $\left(F_{0}=3\right.$ min, the "botulinum cook") and an additional heat-treatment to guarantee microbiological stability. Microbial spoilage of canned food is often caused by thermophilic and highly heat-resistant spore-forming bacteria such as Geobacillus stearothermophilus in the food industry (Logan and De Vos, 2009; Burgess et al., 2010; Prevost et al., 2010). The canned food $F_{0}$ value observed in industry is strongly related to the heat resistance of the strains isolated. G. stearothermoplilus has been regularly isolated from products treated at moderate or high heat levels ( $F_{0}$ between 5 and 20 min and $F_{0}$ above 20 min) (Andre et al, 2013). It is speculated that spores in these products may come from the soil or may result from sporulation during the storage conditions and treatment of ingredients. In cooked food, a variety of ingredients are involved and may carry microbial contaminants (Membre and van Zuijlen, 2011). Despite a long history of description of these

*Corresponding author. Tel: +81-72-740-3300, Fax: +81-72758-6934 E-mail: miyo_nakano (a)shokuken.or jp bacteria, the origin of spores in canned food is poorly understood.

Developments in molecular technique enable faster and more sensitive analysis than classical microbiological procedures. Real-time PCR based identification and quantification is a suitable alternative because it is a comparatively easy, rapid and simple method (Postollec et al., 2011) and it can be completed within several hours. Real-time PCR techniques have been developed with a wide variety of microorganisms, with emphasis on the main food-borne pathogens responsible for substantial medical and economic problems. In the last two decades, culture-independent techniques have greatly improved our understanding of the composition, activities, and dynamics of microbial communities. Nowadays, PCR-based methods, in particular quantitative PCR, are predominantly used to detect, identify and quantify both pathogens and beneficial microbial species, such as fermenting microbes or probiotics (Le Drean et al., 2010, Malorny et al., 2008). ISO standards have also been established, and provide guidelines to quantitatively detect food-borne pathogens by PCR (ISO 22174: 2005, ISO/TS 20836: 2005, ISO 20837: 2006, ISO 20838:2006). 
PCR is a faster, more sensitive, and more specific method than traditional culture-based techniques, and enable detection of sub-dominant populations, even in the absence of a selective enrichment medium and in the presence of other dominant populations. Furthermore, combined with reverse transcription (RT), quantitative PCR can also estimate transcript amounts, therefore providing information on microbial gene activity (Postollec et al., 2011). In this study, we developed a real-time PCR assay for identification and quantification of $G$. stearothermophilus, and applied the direct detection of this species to the examination of samples from commercial canned food.

A total of 35 strains from 30 bacterial species, including four G. stearothermophilus strains, and other close and distant genera, listed in Table 1, were used for primer specificity studies. Geobacillus group strains were incubated at $55-60{ }^{\circ} \mathrm{C}$ in Nutrient Broth (EIKEN CHEMICAL Co., LTD. Tokyo, Japan). Both aerobic and anaerobic other thermophilic strains were incubated at $55-60^{\circ} \mathrm{C}$ according to the reference of growth information.

Genomic DNA was extracted using an Ultra clean DNA isolation kit (MO BIO Laboratories, Carlsbad, CA, USA) following the manufacturer's instructions with minor modifications for the extraction of genomic DNA including spore DNA (Rose et al., 2011). Briefly, microbial cell pellets were collected from $1 \mathrm{ml}$ of undiluted cell

TABLE 1. Microbial strains used in this study

\begin{tabular}{|c|c|}
\hline Species & Strains and sources ${ }^{* 1}$ \\
\hline Geobacillus stearothermophilus & NBRC $12550^{\top}$ (ATCC 12980) \\
\hline Geobacillus stearothermophilus & NBRC 12983 (ATCC 12976) \\
\hline Geobacillus stearothermophilus & NBRC 13737 (ATCC 7953) \\
\hline Geobacillus stearothermophilus & NBRC $100862 （ D S M 1550 ）$ \\
\hline Geobacillus caldoxylosilycus & NBRC $107762^{\top}$ (ATCC 700356) \\
\hline Geobacillus jurassicus & NBRC 107829 (DSM 15726) \\
\hline Geobacillus kaustophilus & NBRC $102445^{\top}$ (ATCC 8005) \\
\hline Geobacillus thermoglucosidasius & NBRC 107763 (ATCC 43742) \\
\hline Geobacillus toebii & NBRC 107807'（DSM 14590） \\
\hline Geobacillus zalhae & NBRC $101842^{\top}$ (DSM 18318) \\
\hline Bacillus subtillis & NBRC $13719^{\top}$ (ATCC 6051) \\
\hline Bacillus coagulans & ATCC 80078 \\
\hline Bacilus licheniformis & NBRC $12200^{\top}$ (ATCC 14580) \\
\hline Paenibacillus polymyxa & NBRC 15309 (ATCC 842) \\
\hline Staphylococcus aureus & NBRC 100910 (ATCC 12600) \\
\hline Escherichia coli & NBRC $102203^{\top}$ (ATCC 11775) \\
\hline Clostridium acetobutylicum & NBRC $13948^{\top}$ (ATCC 824) \\
\hline Clostridium clariflavum & NBRC $101661^{\top}$ (DSM 19732) \\
\hline Clostridium kluyveri & NBRC $12016^{\top}$ (DSM 555) \\
\hline Clostridium thermocellum & NBRC 103400 (ATCC 27405) \\
\hline Moorella thermoacetica & JCM 9319 (ATCC 35608) \\
\hline Moorella thermoacetica & JCM 9320( (ATCC 39073) \\
\hline Moorella thermoacetica & 24-1（our collection） \\
\hline Moorella glycerini & DSM $11254^{\top}$ \\
\hline Moorella humiferrea & DSM $23265^{\top}$ \\
\hline Moorella mulderi & DSM $14980^{\top}$ \\
\hline Moorella stamsii & DSM $26217^{\top}$ \\
\hline Moorella thermoautotrophica & DSM $1974^{\top}$ \\
\hline Moorella perchloratireducens & ATCC BAA-1531 \\
\hline Ammonifex sp. & NBRC 100904 \\
\hline Caldanaerobacter sybterraneus subsp. tengcongensis & NBRC $100824^{\top}$ \\
\hline Carboxydothermus pertinax & NBRC $107576^{\top}$ (DSM 23698) \\
\hline Tepidanaerobacter syntrophicus & NBRC $100060^{\top}$ (DSM 15584) \\
\hline Thermaneromonas toyohensis & NBRC $101528^{\top}$ (DSM 14490) \\
\hline Thermanaerobacter cellulolyticus & NBRC 14436 \\
\hline
\end{tabular}

${ }^{* 1}$ NBRC, NITE Biological Resource Center (Kisarazu, Chiba, Japan); T, type strain; references in parentheses indicate the corresponding reference number in an alternative collection, ATCC, American Type Culture Collection (Manassas, VA. USA), DSM, German Collection of Microorganisms and Cell Cultures (Braunschweig, Germany). 
suspension and then resuspended in $300 \mu \mathrm{L}$ of

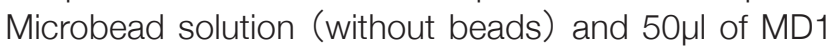
solution. Suspensions were heated at $95{ }^{\circ} \mathrm{C}$ for $20 \mathrm{~min}$ and then centrifuged at $10,000 \times g$ for 2 min. Three hundred microliters of the supernatant were added to $100 \mu \mathrm{l}$ of MD2 solution, and then tubes were inverted several times, incubated at $4{ }^{\circ} \mathrm{C}$ for $10 \mathrm{~min}$, and centrifuged at 10,000 $\times g$ for 2 min. Three hundred microliters of the supernatant were then added to $900 \mu \mathrm{l}$ of MD3 solution. Two $600 \mu$ aliquots of supernatant/MD3 solution were sequentially added to the spin column and centrifuged at $10,000 \times g$ for $30 \mathrm{~s}$. Each flowthrough was discarded. Three hundred microliters of solution MD4 were then added to the spin column, centrifuged as above, and the flow-through was discarded. One hundred microliters of solution MD5 were added to the spin column, which was then centrifuged at $10,000 \times g$ for $1 \mathrm{~min}$ and the flow-through was retained for PCR and real-time PCR assays. For all other reference strains, pure cultures were grown, and bacterial DNA was extracted using an Ultra clean DNA isolation kit following the manufacturer's instructions (MO BIO). Finally, genomic DNA concentrations were determined using a spectrophotometer ( $\mu$ Quant, BioTek Instruments, Inc., USA) and diluted to the appropriate concentration prior to use.

The $16 \mathrm{~S}$ rRNA gene of $G$. stearothermophilus NBRC $12550^{\top}$ was chosen as the target for amplification. Overall, sequences from 120 bacterial species including Geobacillus species, species belonging to a different genus from Bacillaceae such as Bacillus, Listeria, Paenibacillus, Sporolactobacillus, others belonging to Clostridium, and non-related taxa were obtained from the GenBank nucleotide database at the National Center for Biotechnology Information (http://www.ncbi. nlm.nih.gov/genbank/), and from the National Institute of Technology and Evaluation Biological Resource Center (http://www.nbrc.nite.go.jp/e/). Alignment of the 16S rRNA gene sequence from $G$. stearothermophilus and other related and nonrelated taxa was performed with ClustalX (Thompson et al., 1997). Based on the alignment, four primer pairs were selected using Primer3Plus (http://www.bioinformatics.nl/ (a)

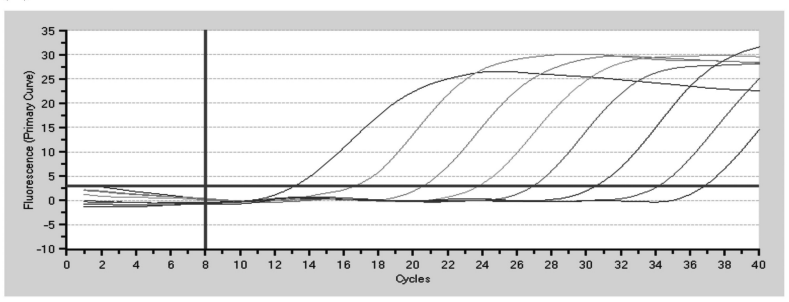

(b)

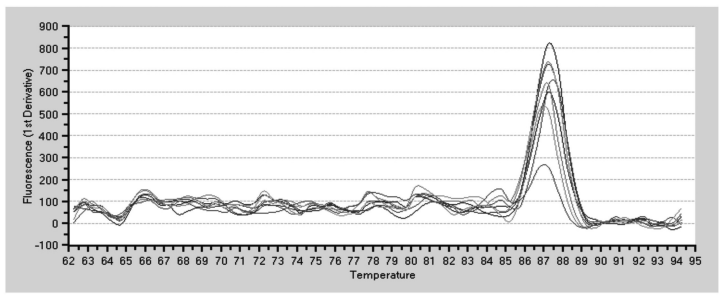

(c)

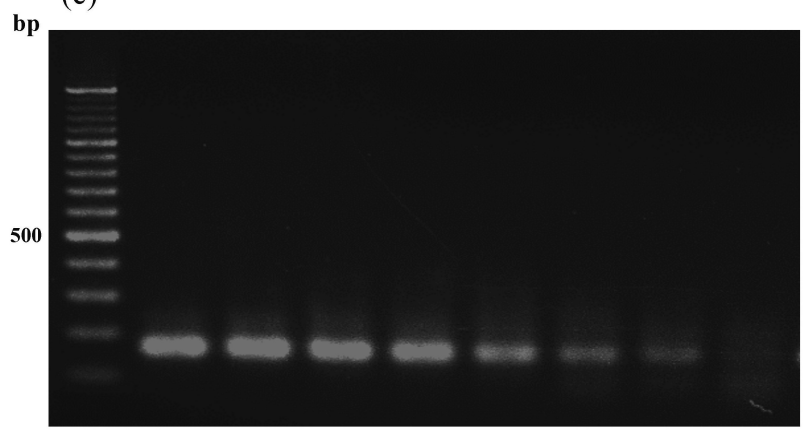

FIG. 1. (a) Amplification curve profiles. (b) Melting curve profiles. (c) Gel images of electrophoresis of 10-fold serial diluted standard curves of Geobacillus stearothermophilus NBRC $12550^{\top}$ from real-time PCR.

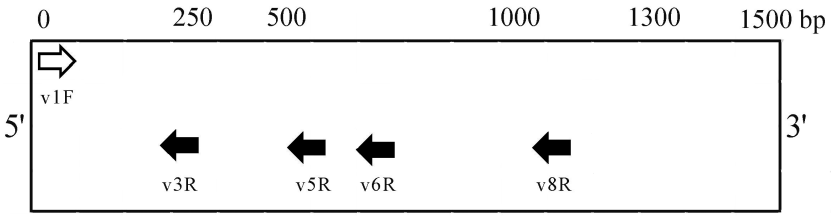

Supporting information Fig.1. Image of primer positions in the nucleotide sequence of the 16S rRNA gene of Geobacillus stearothermophilus strain NBRC $12550^{\top}$

TABLE 2. DNA sequence of primers used in this study

\begin{tabular}{|c|c|c|c|c|c|}
\hline $\begin{array}{l}\text { Primer } \\
\text { name }\end{array}$ & $\begin{array}{c}\text { Primer sequence }\left(5^{\prime}-3^{\prime}\right)^{* 1} \\
\text { Forward }\end{array}$ & $\operatorname{Tm}\left({ }^{\circ} \mathrm{C}\right)$ & $\begin{array}{l}\text { Primer } \\
\text { name }\end{array}$ & $\begin{array}{c}\text { Primer sequence }\left(5^{\prime}-3^{\prime}\right) * 1 \\
\text { Reverse }\end{array}$ & $\operatorname{Tm}\left({ }^{\circ} \mathrm{C}\right)$ \\
\hline Gv $1 F$ & GATTGGGGCTTGCCTTGA & 66.1 & $\begin{array}{l}\text { Gv3R } \\
\text { Gv5R } \\
\text { Gv6R } \\
\text { Gv8R }\end{array}$ & $\begin{array}{l}\text { GCAAGTGACAGCCCAAAGG } \\
\text { GGCTICACATCAGACTAAGAGACC } \\
\text { TCAGGTGCAGGCCAGAGA } \\
\text { ACCGAATGCTGGCAACTAGAG }\end{array}$ & $\begin{array}{l}65.8 \\
66 \\
66.2 \\
65.3\end{array}$ \\
\hline
\end{tabular}

${ }^{* 1}$ Primer design was carried out using Primer 3Plus (http://www.bioinformatics.nl/cgi-bin/primer3plus/ primer3plus.cgi). 
cgi-bin/primer3plus/primer3plus.cgi; Untergasser et al., 2007). Primer sequences are listed in Table 2. Primer positions in the G. stearothermophilus 16S rRNA gene region are illustrated in Supporting Information Fig. 1. The overall theoretic specificities of the newly designed primers were checked using BLAST search.

Quantitative PCR was performed using SYBR Green chemistry. The reactions were carried out in a $25 \mu \mathrm{L}$ volume containing $12.5 \mu \mathrm{L}$ of $2 \times$ SYBR Premix Ex Taq (Tli RNaseH Plus) (Takara Bio, Shiga, Japan), $0.2 \mu \mathrm{M}$ of each primer, $1 \mu \mathrm{L}$ of microbial genomic DNA template, and 5 to $10 \mu \mathrm{L}$ of DNA samples from canned food samples, in a Thermal Cycler Dice Real Time System TP800 (Takara Bio). The optimum cycling parameters were: $95^{\circ} \mathrm{C}$ for $30 \mathrm{~s}$, followed by 36 cycles of $95^{\circ} \mathrm{C}$ for $10 \mathrm{~s}, 62^{\circ} \mathrm{C}$ for $30 \mathrm{~s}$, and $72^{\circ} \mathrm{C}$ for $1 \mathrm{~min}$. A melting curve was generated after the last amplification cycle using a temperature range of $64-95^{\circ} \mathrm{C}$, and a temperature transition rate of $0.5^{\circ} \mathrm{C}$. The cycle threshold $\left(\mathrm{C}_{t}\right)$ and the melting temperature of amplification products were calculated automatically. The amplicon obtained from real-time PCR analysis was confirmed as a single DNA band that corresponded to the expected product size. Negative controls and all non-Geobacillus strains showed no peaks in the melting profiles. The absence of nonspecific products and primer dimers was confirmed by agarose gel electrophoresis.

Among the designed four primer sets, Gv1F ( 5'-GATTGGGGCTTGCCTTGA-3') and Gv3R (5'-GCAAGTGACAGCCCAAAGG-3') were successfully used for species-specific detection of $G$. stearothermophilus by real-time PCR assay. Using $50 \mathrm{pg}$ of template DNA from non-G. stearothermophilus strain (Table 1), no $C_{t}$ reading was obtained within the 36 amplification cycles for any of the isolates (data not shown). The amplicon obtained from real-time PCR analysis was confirmed as a single band that corresponded to the expected product size (Fig. 2). Negative controls and all non-G. stearothermophilus strains also showed no peaks in the melting profiles. The reproducible distinct melting points $\left(T_{m}\right)$ was $87.3^{\circ} \mathrm{C}$ (Fig. 2). The other primer pairs Gv1F/Gv5R and Gv1F/Gv6R demonstrated poorer results than Gv1F/Gv3R in terms of productivity. Consequently, the primer pair Gv1F/Gv3R was used for the specific detection and quantification of this species in this study.

The sensitivity and efficiency of the real-time PCR assays was determined using purified genomic DNA from the representative $G$. stearothermophilus NBRC $12550^{\top}$ strain. Genomic DNA was extracted in triplicate from undiluted cell suspension samples $\left(O_{600}=\right.$ 0.2-0.3) and the DNA concentration quantified. As a result, three individual suspensions of $G$. stearothermophilus with optical densities of 0.254, 0.229, and
0.234 at $600 \mathrm{~nm}$ were prepared, and the corresponding cell counts were respectively determined to be $3.8 \times$ $10^{7} \mathrm{CFU} / \mathrm{mL}, 2.6 \times 10^{7} \mathrm{CFU} / \mathrm{mL}$, and $7.1 \times 10^{7} \mathrm{CFU} / \mathrm{mL}$

(A)

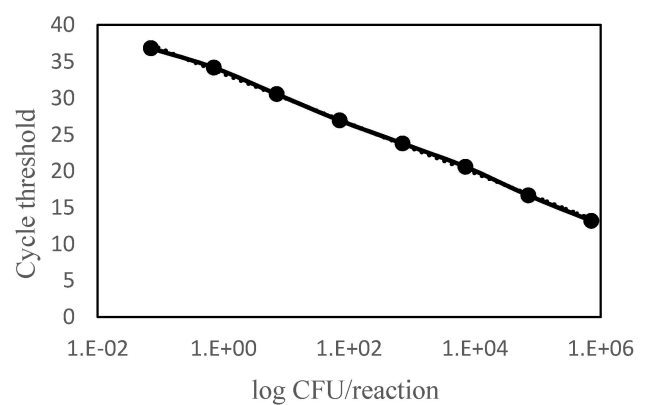

(B)

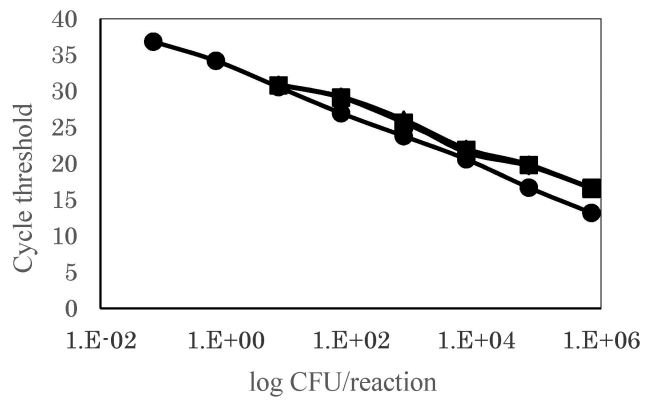

(C)

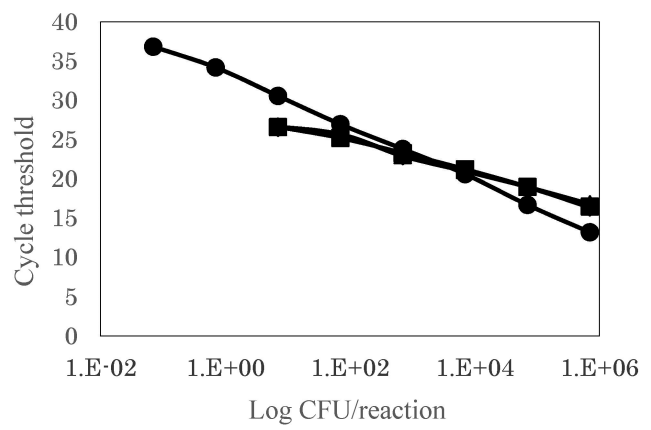

FIG. 2. (A) Standard curve ( $\mathrm{O}$ ) obtained by plotting log CFU/reaction against the $C_{t}$ obtained from real-time PCR analysis of serially diluted solutions of DNA extracted from $G$. stearothermophilus NBRC $12550^{\top}$. The linear regression equation was $y=-1.48( \pm 0.1) \ln (x)+33.356$ ( \pm 0.302$)$ with a coefficient of determination of $R^{2}=0.9954-0.9989$. PCR efficiencies were $96.1 \%$ to $127.9 \%$. Additionally shown are spiking experiment curves used to evaluate the efficiency of this method for detection of $G$. stearothermophilus from samples containing non-target species. (B) Spiking experiment curves from canned whole corn. The linear regression equation was $y=-1.309( \pm 0.057) \ln (x)+34.176( \pm 0.505)$ with a coefficient of determination of $R^{2}=0.9863-0.9917$. (C) Spiking experiment curves from boiled azuki-beans. The linear regression equation was $y=-0.893( \pm 0.011) \ln (x)$ +28.85 ( \pm 0.049 ) with a coefficient of determination of $\mathrm{R}^{2}=0.9879-0.9923$. The symbols $(\boldsymbol{\Delta}),(\boldsymbol{\nabla})$, and ( $\left.\boldsymbol{\square}\right)$ indicated spiked 1, spiked 2, and spiked 3, respectively. 
based on the plate counting of colonies. The genomic DNA concentrations of these individual samples were $14.5 \mathrm{ng} / \mu \mathrm{L}, 9.5 \mathrm{ng} / \mu \mathrm{L}$, and $12.5 \mathrm{ng} / \mu \mathrm{L}$, respectively. Consequently, a 10-fold serial dilution series with concentrations ranging from $12.5 \mathrm{ng}$ to $1.25 \mathrm{fg}$ was prepared using sterile distilled water. Standard curves using $G$. stearothermophilus were produced by plotting the $C_{t}$ values from three replicate PCR assays against the bacterial count (Fig. 2A).

For the extraction of DNA from commercial canned food for detecting the species of $G$. stearothermophilus, sample preparation was conducted as follows. Five kinds of samples that included two different brands of canned whole corn, boiled-beans (azuki bean, Vigna angularis), boiled mushrooms, and boiled-shellfish (Manila clam, Ruditapes philippinarum) were used. In the first step, individual canned samples were treated by sonication for $5 \mathrm{~min}$. Then, microbial pellets were collected from the submerged liquid samples (approximately 25 to $40 \mathrm{ml}$ ) by centrifugation at $7,800 \times \mathrm{g}$ for 40 min at $4{ }^{\circ} \mathrm{C}$, and the pellets were washed three times with phosphate buffered saline (PBS, $\mathrm{pH}$ 7.4). Then, microbial DNA was extracted according to the manufacturer's instructions, with minor modifications mentioned above.

Conventional PCR analysis was also carried out using Emerald Amp PCR Master Mix (Takara Bio) in an S1000 Thermal Cycler (Bio-Rad, Hercules, CA, USA). Thermal cycling conditions were as follows: $95^{\circ} \mathrm{C}$ for 4 min, 30 cycles of $95^{\circ} \mathrm{C}$ for $30 \mathrm{~s}, 62^{\circ} \mathrm{C}$ for $30 \mathrm{~s}, 72^{\circ} \mathrm{C}$ for $1.5 \mathrm{~min}$, followed by $72^{\circ} \mathrm{C}$ for $7 \mathrm{~min}$. Amplification products were separated on 1.5\% (w/v) agarose gels and stained with ethidium bromide. For all of the primer pairs, the minimum detection sensitivity was $125 \mathrm{fg}$, which is equivalent to approximately $7.1 \mathrm{CFU} / \mathrm{mL}$ of $\mathrm{G}$. stearothermophilus. Meanwhile, primer pairs Gv1FGv5R, and Gv1F-Gv8R amplified a secondary weak product in addition to the single amplicon of the expected size. Therefore, Gv1F-Gv3R and Gv1F-Gv6R were suitable primer sets for the conventional PCR assay.

In the spiking experiments, the quantitative PCR assay was tested for its ability to detect $G$. stearothermophilus in canned food containing a diversity of nonpathogenic microorganisms. The microbial pellets were prepared form liquid samples of canned whole corn and boiled-beans (azuki beans, Vigna angularis), respectively. $1 \mathrm{ml}$ of $\mathrm{G}$. stearothermophilus microbial cell suspension $\left(\mathrm{OD}_{600}=0.291\right)$ was serially diluted and submerged into Geobacillus-free microbial pellets derived from canned food samples (whole corn and boiled azuki-beans). These pellets were prepared to confirm the negative results in the real-time PCR assay with a 40-cycle amplification. Microbial DNA was then extracted from the pellets as described above. Then, genomic DNA extracted from the spiked samples was subjected to real-time PCR, and the $C_{t}$ values were plotted (Fig. 2B and 2C). The results for whole corn samples were $y=-1.309( \pm 0.057) \ln (x)+34.18$ ( \pm 0.505 ) and $R^{2}=0.9863$ to 0.9917 , and for boiled azukibeans were $y=-0.893( \pm 0.011) \ln (x)+28.85( \pm 0.049)$, and $R^{2}=0.9879$ to 0.9923 .

The results revealed $C_{t}$ values ranging from $10^{1}$ to $10^{6}$ $\mathrm{CFU} / \mathrm{mL}$, and each curve was highly linear. The statistical analyses revealed no significance differences ( $P>0.05)$ among the slopes, intercepts, and $R^{2}$ values between the spiked results from whole corn and the reference $G$. stearothermophilus strain (Fig. 2B). Meanwhile, there were significant differences $(P<0.05)$ among slopes, intercepts between the spiked results from boiled-beans and the reference $G$. stearothermophilus strain (Fig. 2C). We concluded that amplification efficiency and target gene detection were not affected by the presence of non-target microbial DNA, except for when target DNA was only present in low concentrations. Furthermore, this method may be affected by the genomic DNA extraction efficiency when only a small amount of target DNA was present together with non-target DNA, and different types of food samples were assayed.

To identify G. stearothermophilus from canned food, samples were prepared as described above, and subjected to the real-time PCR assay by using the primer pair Gv1F-Gv3R. The $C_{t}$ values obtained from the assay were used to calculate the $\mathrm{CFU} / \mathrm{ml}$ of $\mathrm{G}$. stearothermophilus in each sample on the standard curve (Fig. 2A). As for the detection limit by using the primer pair Gv1F-Gv3R, the assay theoretically allowed the estimation of numbers of microorganisms to 0.65 $\mathrm{CFU} / \mathrm{mL}$. Quantitative real-time PCR results showed negative results for $G$. stearothermophilus in all samples. Meanwhile, a conventional PCR assay and a direct incubation produced negative results for all samples. It was suggested these organisms 1) may not be major inhabitants of phyllosphere environments of vegetable tissues and/or marine foods, or 2) may be inactive due to treatments during the processing of canned products.

In addition, in a one-step incubation, the pellets from canned food submerged samples were incubated at 55 ${ }^{\circ} \mathrm{C}$ for 10 days, and one hundred microliter samples were spread onto nutrient agar plates and incubated at $55^{\circ} \mathrm{C}$ for 3 days. The colony formation was observed (at least $>10^{3} \mathrm{CFU} / \mathrm{ml}$ ) for boiled-beans. Two colonies were picked up randomly and subjected to genomic DNA extraction and sequence determination for the identification of microorganisms. Based on the phylogenetic analysis of $16 S$ rRNA sequences, these strains 
were found to be identical to that of G. stearothermophilus at $97 \%$ and $95 \%$, respectively. It was suggested these spores may have been germinated through incubation at $55^{\circ} \mathrm{C}$. The discrepancy in the results between real-time PCR and incubation analyses from boiledbean samples must to be explored in further analyses. Taken together, it suggests that measures such as additional heat treatment and the riak assessment of the storage environments might be needed ot ensure the adequate handling of canned food.

Andre et al. (2013) investigated the bacterial species responsible for non-stability after prolonged incubation of low acid canned food at $55{ }^{\circ} \mathrm{C}$ by examining 455 samples collected from 122 French canneries over 10 years. These results showed three genera were responsible for more than $80 \%$ of all non-stability cases: mostly Moorella (36 \%) and Geobacillus (35\%), and less frequently Thermoanaerobacterium (10\%). Among thermophilic bacteria, G. stearothermophilus is recognized as a major cause of spoilage in canned foods and is frequently detected after a 7-day incubation at $55^{\circ} \mathrm{C}$ (Andre et al., 2013). Recently, Prevost et al. (2010) reported that thermophilic bacteria including G. searothermophilus, M. thermoacetica/M. thermoautotrophica, and Thermoanaerobacerium group were detected in canned food spoilage via cultivation methods. Thermophilic bacteria spores were counted in 13 ingredients such as spices, milk powder and aromas (Prevost et al., 2010). In the past, several studies pointed out that thermophilic bacteria spore contamination occasionally occurred, particular, in milk powder produced by a heating process (Cooper et al., 2006, Ruckert et al., 2004). The ingredients may be the entrance point for highly heat resistant bacteria in food (Oomes et al., 2007). Thus, spore contamination in canned food may be related to the inclusion of various kinds of ingredients susceptible to microbial contamination. In addition, spore contamination probably comes from the soil or may result from sporulation during food processing. Hence, control of the large diversity of spore-forming microorganisms in the food environment and adjustment of food retort settings should be based on data collection about spore contamination levels in ingredients and raw materials. In order to optimize sterilization processes, the heat resistance of contaminating spores must be considered.

In this study, a highly specific real-time PCR assay was established to detect and quantify G. stearothermophilus in canned food. This method is highly reliable, rapid and can be directly performed within several hours. The current approach could be useful for tracking and monitoring bacterial contaminants in various kinds of food and/or food ingredients. Screening for the spoilage-causing microorganisms in raw mate- rials, ingredients and samples from processing lines could help identify points or sites of contamination in canned food industry for improve safety management and hygiene control.

\section{ACKOWLEDGEMENTS}

The author thanks Yoshio Aoyama (principal investigator, division of food science, Toyo Institute of Food Technology) for his helpful advice and suggestions throughout the study.

\section{REFERENCES}

Andre, S., Zuver, F., and Remize, F. (2013) Thermophilic spore-forming bacteria isolated spoiled canned food and their heat resistance. Results of a French ten-year survey. Int. J. Food Microbiol. 165, 134-143.

Burgess, S. A., Lindsay, D., and Flint, S. H. (2010) Thermophilic bacilli and their importance in daily processing. Int. J. Food Microbiol. 144, 215-225.

Cooper, R. M., and McKillip, J. L. (2006) Enterotoxigenic Bacillus spp.. DNA fingerprint revealed in naturally contaminated nonfat dry milk powder using rep-PCR. J. Basic. Microbiol. 46, 358-364.

Le Drean, G., Mounier, J., Vasseur, V., Arzur, D., Habrylo, O., and Barbier, G. (2010) Quantification of Penicillium camemberti and $P$. roqueforti mycelium by real-time PCR to assess their growth dynamics during ripening cheese. Int. J. Food Microbiol. 138, 100-107.

Logan, N. A., and De Vos, P. (2009) Genus Bacillus Cohn 1872. In Bergey's Manual of Systematic Bacteriology, $2^{\text {nd }}$ edn, vol. 3, pp, 21-128. Edited by P. Vos, G. Garrity, D. Jhons, N. R. Kreig, W. Ludwig, F. A. Rainet, K.-H. Schleifer \& W. B. Whitman. New York: Springer-Verlag.

Malorny, B., Lofstom, C., Wagner, M., Kramer, N., and Hoorfar, J. (2008) Enumeration of salmonella bacteria in food and feed samples by real-time PCR for quantitative microbial risk assessment. Appl. Environ. Microbiol. 74, 1299-1304.

Membre, J. M., and van Zuijlen, A. (2011) A probabilistic approach to determine thermal process setting parameters: application for commercial sterility of products. Int. J. Food Microbiol. 144, 413-420.

Oomes, S. J., van Zuijlen, A. C., Hehenkamp, J. O., Witsenboer, H., van der Vossen, J. M., and Brul, S. (2007) The characterization of Bacillus spores occurring in the manufacturing of (low acid) canned products. Int. J. Food Microbiol. 120, 85-94.

Postollec, F., Falentin, H., Pavan, S., Combrisson, J., and Sohier D. (2011) Recent advances in quantitative (qPCR) applications in food microbiology Food Microbiol. 1-14.

Prevost, S., Andre, S., and Remize, F., (2010) PCR detection of thermophilic spore-forming bacteria involved in canned food spoilage. Curr. Microbiol. 61, 525-533.

Ruckert, A., Ronimus, R. S., and Morgan, H. W. (2004) A RAPD-based survey of thermophilic bacilli in milk powder from different countries. Int. J. Food Microbiol. 96, 263-272.

Rose, H. L., Dewey, C. A., Ely, M. S., Willoughby, S. L., Parsons, T. M., Cox, V., Spencer, P. M., and Weller, S. A. (2011) Comparison of eight methods for the extraction of Bacillus atrophaeus spore DNA from eleven common inter- 
ferents and a common swab. PLoS ONE. 6: e22668

Thompson, J. D., Gibson, T. J., Plewniak, F., Jeanmougin, F., and Higgins, D. G. (1997) The clustal X windows interface: Flexible strategies for multiple sequence alignment aided by quality analysis tools. Nucleic Acids Res. 25,
4876-4882.

Untergasser, A., Nijveen, H., Rao X-Y., Bisseling, T., Geurts, R., and Leunissen, J. A. M. (2007) Primer3Plus, an enhanced web interface to Primer3 Nucleic Acids Research 35, W71-W74; doi:10.1093/nar/gkm306 